\title{
Amfepramone does not cause primary pulmonary hypertension
}

\section{To the Editor:}

The article by ABRAMOwICZ et al. [1] should show the first case of primary pulmonary hypertension (PPH) associated with the use of amfepramone (diethylpropion), an anorectic drug, and BMPR2 mutation. In my opinion, the relationship between amfepramone and the rise of PPH in this case is unproven.

BMPR2 mutation is related to PPH without use of anorectics. Autosomal dominant germline mutations in BMPR2 have been identified in $55 \%$ of familial cases and in $25 \%$ of patients with negative family history [2].

There are three different types of anorectic drugs: fenfluramines (fenfluramine and dexfenfluramine), serotonin releasers; noradrenergic agents (i.e. amfepramone), noradrenaline releasers; and sibutramine, a noradrenaline and serotonin reuptake inhibitor [3].

It is true that BMPR2 mutations combined with exposure to fenfluramine derivatives increase the risk of developing $\mathrm{PPH}$, but the mechanisms of the lesions, with any probability, are associated with the serotoninergic pathway [4-6]. Amfepramone is a noradrenaline releaser and not a serotonin stimulant.

However, after ABENHAIM et al. [7] showed a correlation between anorectics and PPH, a second much larger study was performed in the USA [8]. This study showed that: 1) only the use of fenfluramines for $\geqslant 6$ months remained associated with the diagnosis of PPH; and 2) when only recent users of fenfluramines (i.e. those using them in the 6 months preceding diagnosis) were counted as exposed, the associated adjusted odds ratios from the logistic regression that reflected the directions of associations were higher.

Therefore: 1) Abramowicz's patient had a mutation, which could, per se, cause $\mathrm{PPH}$; 2) there are no data that amfepramone causes PPH; 3) a direct relationship between noradrenergic pathway and PPH has never been supposed; 4) the exposure to anorectic drug was too short; and 5) the period between amfepramone use and the onset of symptoms is too long.

Considering this case, if we use the common algorithms for the assessment of adverse drug reactions [9-11], the result is unlikely. It is very difficult to be able to suppose that the use of amfepramone could have any relationship, even indirectly, in the rise of primary pulmonary hypertension.

\section{G. Di Sacco}

Dept of Endocrinology, Niguarda Hospital, Milan, Italy.

\section{References}

1. Abramowicz MJ, Van Haecke P, Demedts M, et al. Primary pulmonary hypertension after amfepramone (diethylpropion) with BMPR2 mutation. Eur Respir J 2003; 22: 560-562.

2. Rindermann M, Grunig E, von Hippel A, et al. Primary pulmonary hypertension may be a heterogeneous disease with a second locus on chromosome 2q31. J Am Coll Cardiol 2003; 41: 2237-2244.

3. Bray GA, Greenway FL. Current and potential drugs for treatment of obesity. Endocr Rev 1999; 20: 805-875.

4. Kereveur A, Callebert J, Humbert M, et al. High plasma serotonin levels in primary pulmonary hypertension. Effect of long-term epoprostenol (prostacyclin) therapy. Arterioscler Thromb Vasc Biol 2000; 20: 2233-2239.

5. Eddahibi S, Raffestin B, Hamon $\mathrm{M}$, et al. Is the serotonin transporter involved in the pathogenesis of pulmonary hypertension? J Lab Clin Med 2002; 139: 194-201.

6. Rondelet B, Van Beneden R, Kerbaul F, et al. Expression of the serotonin $1 \mathrm{~b}$ receptor in experimental pulmonary hypertension. Eur Respir J 2003; 22: 408-412.

7. Abenhaim L, Moride Y, Brenot F, et al. Appetite-suppressant drugs and the risk of primary pulmonary hypertension. International Primary Pulmonary Hypertension Study Group. N Engl J Med 1996; 335: 609-616.

8. Rich S, Rubin L, Walker AM, Schneeweiss S, et al. Anorexigens and pulmonary hypertension in the United States: results from the surveillance of North American pulmonary hypertension. Chest 2000; 117: 870-874.

9. Naranjo C, Busto U, Sellers EM, et al.. Clin Pharmacolz Ther 1981; 30: 239-245.

10. Hutchinson TA, Leventhal JM, Kramer MS, et al. An algorithm for the operational assessment of adverse drug reactions. II: demonstration of reproducibility and validity. JAMA 1979; 242: 633-638.

11. Jones JK. Adverse drug reactions in the community health setting: approaches to recognizing, counselling and reporting. Fam Community Health 1982; 5: 58-67.

\section{From the authors:}

We appreciate G. Di Sacco's comments and acknowledge the limitations of the single-case association we report [1]. However, we believe it is worthy of attention. Our patient is interesting as she took amfepramone only, without fenfluramine, which is uncommon. Amfepramone-only cases are indeed so scarce that the study by ABENHAIM et al. [2] and similar studies could not confirm or rule out an association with primary pulmonary hypertension $(\mathrm{PPH})$.

G. Di Sacco is being merely semantic when quoting a BMPR2 mutation per se as a cause of PPH. Indeed, the penetrance of the mutation is so low, $10-20 \%$, that we must conclude that some other factors are necessary for $\mathrm{PPH}$ to develop.

Our patient developed PPH after use of amfepramone on a short-term basis, as is reported for BMPR2 mutation carriers after fenfluramine [3]. Indeed, you expect to find some BMPR2 mutation carriers in PPH patients without anorexigen use. However, the frequency of BMPR2 mutations observed in PPH after fenfluramine use was much larger than in the general population [2].

This favours a model where fenfluramine is a possible trigger of primary pulmonary hypertension in BMPR2 mutation carriers. Our single-case observation is consistent with this model.

\section{Abramowicz*, M. Delcroix ${ }^{\#}$}

*Genetics Dept, Hôspital Erasme-ULB, Université Libre de Bruxelles, and "Pneumology Dept, Gasthuisberg University Hospital, Katholieke Universiteit van Leuven, Leuven, Belgium. 


\section{References}

1. Abramowicz MJ, Van Haecke P, Demedts M, et al. Primary pulmonary hypertension after amfepramone (diethylpropion) with BMPR2 mutation. Eur Respir J 2003; 22: 560-562.

2. Abenhaim L, Moride Y, Brenot F, et al. Appetite-suppressant drugs and the risk of primary pulmonary hypertension. International Primary Pulmonary Hypertension Study Group. N Engl J Med 1996; 335: 609-616.

3. Humbert M, Deng Z, Simonneau G, et al. BMPR2 germline mutations in pulmonary hypertension associated with fenfluramine derivatives. Eur Respir J 2002; 20: 518-523.

\section{Declaration of conflicts of interest}

\section{To the Editor:}

I am increasingly concerned by the failure of the European Respiratory Journal to require authors to declare competing interests. The most recent example was an editorial by one of the co-editors of the journal, which implied that long-acting bronchodilators and inhaled steroids are more beneficial if given in a combined inhaler device than as separate inhalers [1]. This statement was supported by reference to a review by BARNES [2], also in the Journal, which does indeed state that "in some studies, the fixed combination is even superior to delivery of the two components by separate inhalers". However, this statement was not referenced and the size and clinical significance of any benefit from using a combined inhaler device was not stated. Both experts have rightly referred to a substantial body of evidence that patients with asthma and COPD have been shown to benefit from treatment with two drug classes. However, the reader is asked to accept unreferenced statements that there is additional benefit if the two drugs are delivered from a combined inhaler device.

Although combined treatment is obviously more convenient for patients and may help with compliance/concordance, the cost to the healthcare provider is higher in the UK than the cost of prescribing two inhalers, one containing a longacting $\beta$-agonist and the other containing a generic inhaled steroid equivalent to the dose of budesonide or fluticasone in the combined products. I suspect that the same cost issues will apply in many other countries.

If healthcare providers are to be persuaded by unreferenced statements by distinguished scientists they need to know if the scientist or their department (or journal) have any financial or contractual links with the companies that would profit from increased use of the more expensive products. The December 2003 issue of the European Respiratory Journal, which contains the above-mentioned editorial, also contains paid advertising for both types of combined bronchodilator-steroid inhalers.

\section{R. O'Driscoll}

Hope Hospital, Salford, Greater Manchester, UK.

\section{References}

1. Rabe KF. Combination therapy for chronic obstructive pulmonary disease; one size fits all? Eur Respir $J$ 2003; 22: 874-875.

2. Barnes PJ. Scientific rationale for inhaled combination therapy with long-acting $\beta_{2}$ agonists and corticosteroids. Eur Respir J 2002; 19: 182-191.

\section{From the Editors:}

The editors and the European Respiratory Journal very much welcome responses from our readership on issues published in the Journal! We therefore gladly received comments by R. O'Driscoll in relation to declaration of conflicts of interest that was raised following an editorial [1] written by one of us commenting on a paper on combination therapy for COPD [2].

A slight correction in relation to the letter of R. O'Driscoll should be allowed at this stage, however. The editorial did not reference BARNES [3] as stating that "inhaled steroids are more beneficial if given in a combined inhaler device than as separate inhalers", as was suggested by R. O'Driscoll; it was explicitly stated that the BARNES [3] reference merely gave a "reasonable scientific basis" for the use of combination therapy, indicating the degree of uncertainty that does remain around this issue.

The more relevant point, and here we fully agree with R. O'Driscoll, is the necessity for declaration of conflicts of interest in scientific journals. We as editors acknowledge the necessity to openly address academic-industrial relationships $[4,5]$ by authors and, therefore, the instruction to authors for the European Respiratory Journal clearly state that, "Authors of manuscripts are responsible for recognising and disclosing financial and other conflicts of interest related to the study or to the subject of the review of editorial article. The authors have to acknowledge in a manuscript all financial support for the work and other financial or personal connections to the work". While the instructions for authors are explicit on this issue, the Publication Committee and Executive Committee of the European Respiratory Society together with the editors of the European Respiratory Journal are preparing an even more transparent way to disclose any potential for conflict of interest with statements appended to the articles submitted, a practice that is adopted by more and more reputable journals.

K.F. Rabe, P.J. Sterk

Editors European Respiratory Journal

\section{References}

1. Rabe KF. Combination therapy for chronic obstructive pulmonary disease; one size fits all? Eur Respir $J$ 2003; 22: 874-875.

2. Calverley PM, Boonsawat W, Cseke Z, Zhong N, Peterson S, Olsson H. Maintenance therapy with budesonide and formoterol in chronic obstructive pulmonary disease. Eur Respir J 2003; 22: 912-919.

3. Barnes PJ. Scientific rationale for inhaled combination therapy with long-acting $\mathrm{B}_{2}$ agonists and corticosteroids. Eur Respir J 2002; 19: 182-191.

4. Blumenthal D. Academic-industrial relationships in the life sciences. N Engl J Med 2003; 349: 2452-2459.

5. Bekelman JE, Li Y, Gross GP. Scope and impact of financial conflicts of interest in biomedical research. A systematic review. JAMA 2003; 289: 454 465. 